\title{
Implementation of Learning Principles in Distance Learning through the WhatsApp Application
}

\author{
Implementasi Prinsip-Prinsip Pembelajaran dalam Pembelajaran Jarak Jauh \\ melalui Aplikasi Obrolan WhatsApp
}

\author{
Windi Megayanti \\ Universitas Indraprasta PGRI \\ Jakarta \\ megayantiwindi@gmail.com
}

\begin{abstract}
$\overline{\text { Abstract }}$
This study aims to determine the implementation of learning principles in distance learning through the WhatsApp chat application. The method used in this research is the ex post facto method. This research was conducted on students of the Economic Education Study Program, Faculty of Education and Social Sciences, Indraprasta University, PGRI with a sample of 282 students. The results of this study were as many as $81.9 \%$ of students stated that they could pay attention to learning well, $52.5 \%$ of students felt motivated when participating in learning, $69.5 \%$ of students stated that they were able to actively participate in learning, $62.4 \%$ of students stated that they felt involved when learning takes place, $84.8 \%$ stated that they could re-access the material that had been studied, $49.3 \%$ said the given task could accommodate their understanding, and $54.3 \%$ stated that the complexity of learning could be solved through learning via WhatsApp. Based on this research, it can be concluded that learning principles such as attention and motivation, activeness, direct involvement, repetition, challenges, and individual differences have been implemented well even though learning is carried out remotely through the WhatsApp chat application. However, teachers seem to need to pay attention to the challenges and individual differences in the implementation of distance learning through WhatsApp. This can be seen from the results of the study that the task given with the aim of accommodating understanding turned out to be the lowest number, not even reaching $50 \%$. This shows that there is a need for other innovations in an effort to accommodate understanding in order to facilitate each individual who has differences in understanding each material given.

Keywords: principles of learning, distance learning, WhatsApp
\end{abstract}

Abstrak

Penelitian ini bertujuan untuk mengetahui implementasi prinsip-prinsip pembelajaran dalam pembelajaran jarak jauh melalui aplikasi obrolan WhatsApp. Metode yang digunakan dalam penelitian ini adalah metode ex post facto. Penelitian ini dilaksanakan kepada Mahasiswa Program Studi Pendidikan Ekonomi Fakultas Ilmu Pendidikan dan Pengetahuan Sosial Universitas Indraprasta PGRI dengan sample sebanyak 282 mahasiswa. Hasil dari penelitian ini yaitu sebanyak 81,9\% mahasiswa menyatakan dapat memperhatikan pembelajaran dengan baik, 52,5\% mahasiswa merasa termotivasi saat mengikuti pembelajaran, 69,5\% mahasiswa menyatakan mampu mengikuti pembelajaran secara aktif, $62,4 \%$ mahasiswa menyatakan merasa terlibat saat pembelajaran berlangsung, $84,8 \%$ menyatakan dapat mengakses kembali materi yang telah dipelajari, 49,3\% menyatakan tugas yang diberikan dapat mengakomodasi pemahaman mereka, dan 54,3\% menyatakan bahwa kerumitan pembelajaran dapat dipecahkan melalui pembelajaran via WhatsApp. Berdasarkan penelitian tersebut maka dapat disimpulkan bahwa prinsip-prinsip pembelajaran seperti perhatian dan motivasi, keaktifan, keterlibatan langsung, pengulangan, tantangan, serta perbedaan individu telah diimplementasikan dengan baik meski pembelajaran dilakukan secara jarak jauh melalui aplikasi obrolan WhatsApp. Akan tetapi, pengajar tampaknya perlu memperhatikan tantangan dan perbedaan individu dalam pelaksanaan pembelajaran jarak jauh melalui WhatsApp ini. Hal ini terlihat dari hasil penelitian bahwa tugas yang diberikan dengan tujuan mengakomodasi pemahaman ternyata menunjukkan angka terendah, bahkan tidak mencapai 50\%. Hal ini menunjukkan bahwa perlu adanya inovasi lain dalam upaya mengakomodasi pemahaman agar dapat memfasilitasi setiap individu yang memiliki perbedaan dalam memahami setiap materi yang diberikan.

Kata kunci: prinsip pembelajaran, pembelajaran jarak jauh, WhatsApp 


\section{PENDAHULUAN}

Dalam rangka menerapkan protokol kesehatan di era pandemi Covid-19, pembelajaran tatap muka pun dihindari. Hal ini kemudian menyebabkan proses pembelajaran beralih dari luring menjadi daring. Tentu saja perpindahan proses pembelajaran ini bukan tanpa masalah. Perubahan kondisi yang begitu cepat dan tanpa terencana ini membuat beberapa institusi pendidikan kebakaran jenggot. Terutama mereka yang memang sebelumnya tidak memiliki ruang belajar virtual untuk kegiatan pembelajaran daring.

Dalam rangka memenuhi tuntutan pembelajaran, akhirnya keputusan cepat pun harus segera diambil. Kegiatan pembelajaran tetap harus dilakukan tanpa memberatkan pendidik dan para peserta didiknya. Pembelajaran dari rumah harus segera dilaksanakan meski media pembelajaran yang digunakan oleh institusi pendidikan menjadi masalah utama (Robbani, Rosadi, dan Nurfitria, 2020). Pembuatan ruang belajar virtual bagi masing-masing institusi pendidikan tentu saja memerlukan waktu dan biaya yang tidak sedikit. Selain itu, jika pun ruang belajar virtual ini bisa diwujudkan, tentu saja harus ada pelatihan dan pengenalan fitur penggunaan kepada pendidik juga para peserta didiknya. Artinya, perlu persiapan matang untuk penggunaan ruang belajar virtual tersebut.

Pada akhirnya, beberapa institusi pendidikan menyerahkan sepenuhnya proses pembelajaran kepada pendidiknya dengan kesepakatan bersama para peserta didiknya. Pembelajaran akan berjalan dengan baik, jika kesepakatan dibentuk dengan baik. Sayangnya, beberapa pendidik merasa tak ada waktu lagi untuk berdiskusi, keputusan harus segera dibuat.

Beberapa pendidik menganggap penggunaan aplikasi obrolan online dewasa ini adalah hal yang lumrah. Hampir semua orang berinteraksi dan mengobrol via internet dengan menggunakan aplikasi obrolan online seperti WhatsApp, Telegram, Line, dan lain sebagainya (Megayanti dan Rosadi, 2018). Oleh karena itu, mereka memutuskan untuk melakukan pembelajaran daring melalui aplikasi obrolan online. Selain dianggap sudah populer, penggunaannya pun tidak rumit. Mereka hanya perlu membuat grup obrolan yang di dalamnya nanti akan dibahas materi-materi pembelajaran.

Pustikayasa (2019) mengatakan, dengan penggunaan aplikasi obrolan online ini, pendidik diharapkan tidak hanya melaksanakan pembelajaran berdasarkan kurikulum semata, tetapi juga dapat memberi dorongan untuk membangkitkan, merangsang, dan meningkatkan motivasi belajar peserta didik, sehingga tujuan suatu pembelajaran dapat tercapai dengan baik. Pemanfaatan aplikasi obrolan online ini juga diharapkan mampu membentuk collaboration application dan information sharing, sehingga tujuan pembelajaran daring benar-benar bisa terlaksana (Prajana, 2017).

Peserta didik sebagai subyek sekaligus obyek pembelajaran yang masih dalam tahap perkembangan memerlukan perhatian dan motivasi belajar agar dapat lebih terarah pembelajarannya. Selaku pendidik sangatlah penting untuk mengetahui prinsip-prinsip pembelajaran yang dapat membimbing aktivitas pendidik dalam merencanakan dan melaksanakan pembelajaran agar lebih efektif, meskipun bukan satu-satunya jalan yang dapat menentukan prosedur pembelajaran, namun dapat menjadi pedoman pendidik dalam melaksanakan aktivitas pembelajaran. Prinsip-prinsip yang dimaksud adalah perhatian dan motivasi, keaktifan, keterlibatan langsung, pengulangan, tantangan, serta perbedaan individu (Ali \& Hasniyati, 2013). Untuk itu, penelitian ini bertujuan untuk mengetahui implementasi prinsipprinsip pembelajaran dalam pembelajaran jarak jauh melalui aplikasi obrolan WhatsApp. 


\section{METODE}

Penelitian ini menggunakan metode ex post facto. Penelitian ex post facto merupakan metode yang banyak dipakai dan merupakan metode yang berguna yang dapat memberikan banyak informasi berharga bagi pengambilan keputusan di bidang pendidikan. Istilah ex post facto menunjukkan bahwa perubahan telah terjadi dan peneliti dihadapkan kepada masalah bagaimana menetapkan sebab dari akibat yang sedang diamati. Penelitian ex post facto meneliti hubungan sebab-akibat yang tidak dimanipulasi atau tidak diberi perlakuan oleh peneliti. Penelitian sebab-akibat dilakukan terhadap program, kegiatan, atau kejadian yang telah berlangsung atau telah terjadi. Adanya hubungan sebab-akibat didasarkan atas kajian teoretis, bahwa sesuatu variabel disebabkan atau dilatarbelakangi oleh variabel tertentu atau mengakibatkan variabel tertentu (Sappaile, 2010).

Data diambil dengan metode survei melalui penyebaran kuesioner dalam bentuk online yang disebar kepada mahasiswa Universitas Indraprasta PGRI, Jakarta. Dari survei tersebut, terkumpul sejumlah 282 mahasiswa yang mengikuti pembelajaran online dalam kurun waktu Maret hingga Juli 2020.

\section{HASIL DAN PEMBAHASAN}

\section{Hasil}

Prinsip-prinsip pembelajaran yang dimaksud dalam penelitian ini mengacu pada prinsipprinsip pembelajaran yang disampaikan oleh Ali \& Hasniyati (2013) yaitu perhatian dan motivasi, keaktifan, keterlibatan langsung, pengulangan, tantangan, serta perbedaan individu. Untuk mendapatkan data terkait perhatian, peneliti mengajukan pertanyaan, "Apakah Anda dapat memperhatikan setiap pembelajaran yang diberikan melalui aplikasi obrolan?". Dari pertanyaan tersebut, diketahui sebanyak 231 responden menjawab "Ya", 49 responden menjawab "Mungkin", dan 2 responden menjawab "Tidak". Data tersebut data dilihat pada gambar berikut:

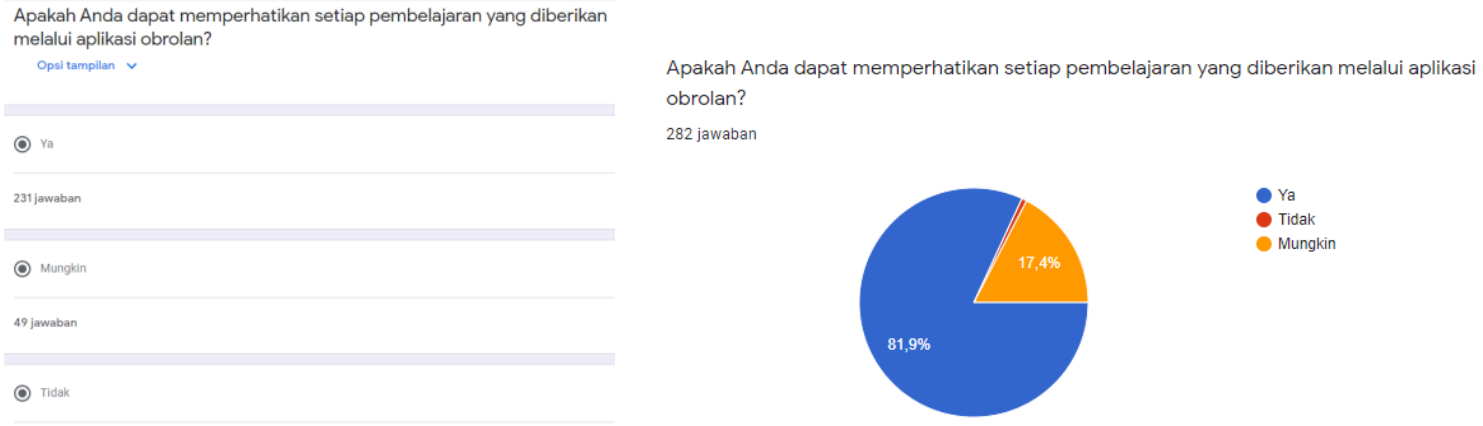

Gambar 1. Rekapitulasi data pertanyaan 1

Adapun untuk mendapatkan data terkait motivasi, peneliti mengajukan pertanyaan, "Apakah Anda merasa termotivasi saat mengikuti pembelajaran melalui aplikasi obrolan?". Dari pertanyaan tersebut, diketahui sebanyak 148 responden menjawab "Ya", 114 responden menjawab "Mungkin", dan 20 responden menjawab "Tidak". Data tersebut data dilihat pada gambar berikut:

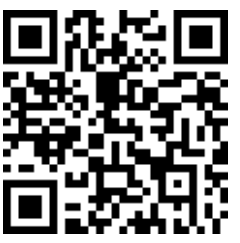

DOI PUBLIKASI https://doi.org/10.37010/int.v2i2 


\section{Implementation of Learning Principles in Distance Learning \\ through the WhatsApp Application \\ Windi Megayanti \\ Universitas Indraprasta PGRI}
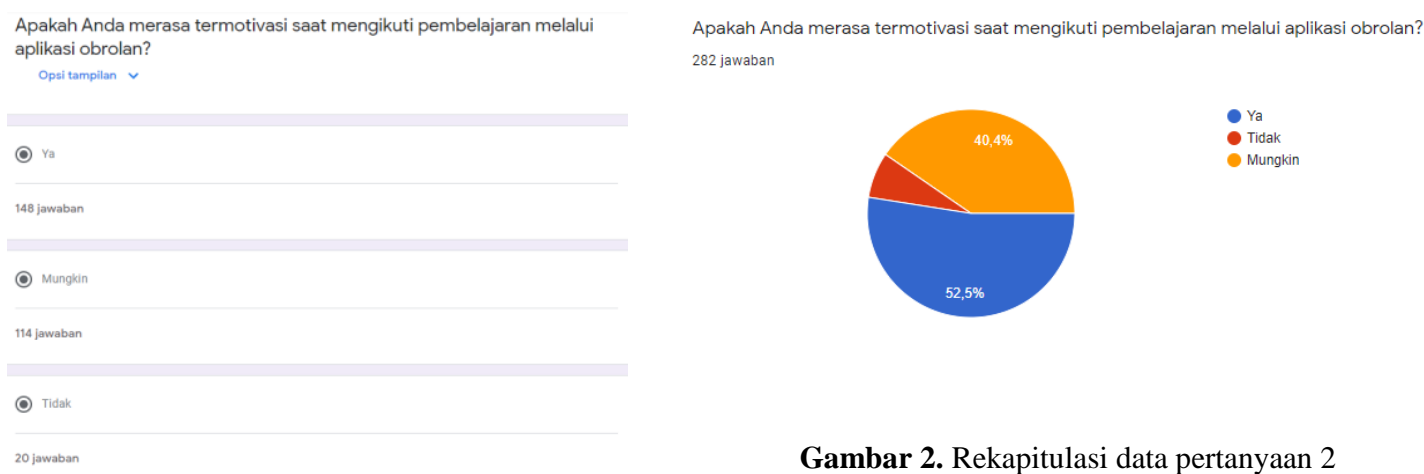

Gambar 2. Rekapitulasi data pertanyaan 2

Adapun untuk mendapatkan data terkait keaktifan, peneliti mengajukan pertanyaan, “Apakah Anda dapat mengikuti pembelajaran secara aktif melalui aplikasi obrolan?". Dari pertanyaan tersebut, diketahui sebanyak 196 responden menjawab "Ya", 75 responden menjawab "Mungkin", dan 11 responden menjawab "Tidak". Data tersebut data dilihat pada gambar berikut:
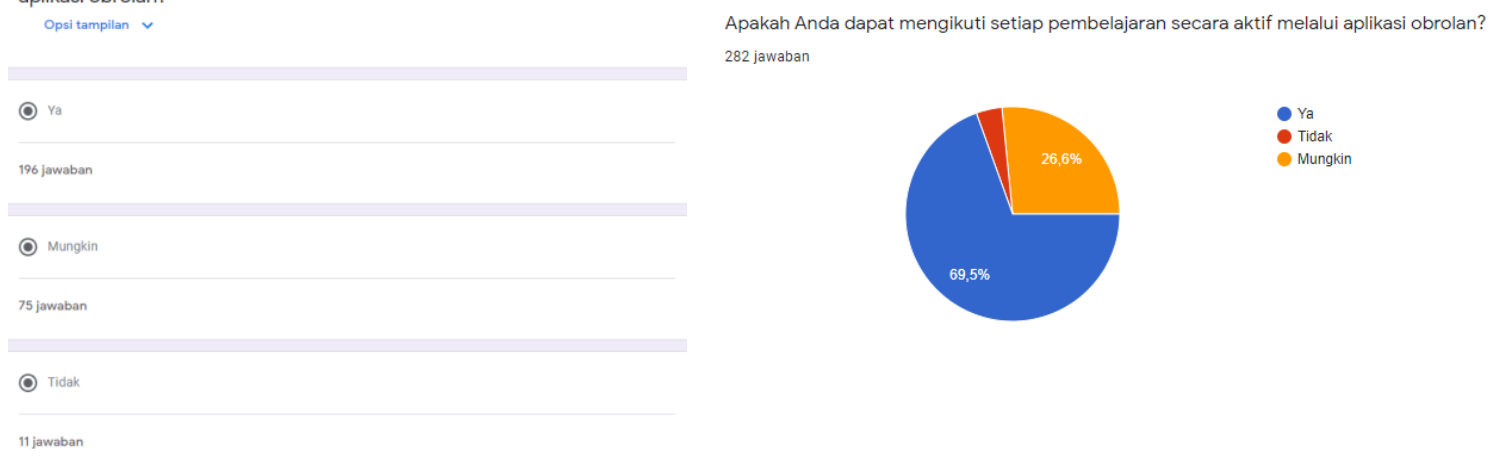

Gambar 3. Rekapitulasi data pertanyaan 3

Adapun untuk mendapatkan data terkait keterlibatan langsung, peneliti mengajukan pertanyaan, "Apakah Anda merasa terlibat saat pembelajaran berlangsung melalui aplikasi obrolan?". Dari pertanyaan tersebut, diketahui sebanyak 176 responden menjawab "Ya", 88 responden menjawab "Mungkin", dan 18 responden menjawab "Tidak". Data tersebut data dilihat pada gambar berikut: 
Apakah Anda merasa terlibat saat pembelajaran berlangsung melalui aplikasi obrolan?

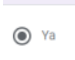

176 jawaban

○ Mungkin

88 jawabar

○ Tidak
Apakah Anda merasa terlibat saat pembelajaran berlangsung melalui aplikasi obrolan? 282 jawaban

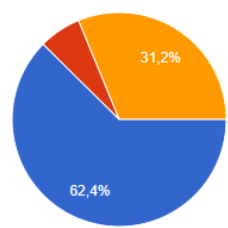

Gambar 4. Rekapitulasi data pertanyaan 4

Adapun untuk mendapatkan data terkait pengulangan, peneliti mengajukan pertanyaan, "Apakah Anda dapat mengakses kembali materi yang telah dipelajari melalui aplikasi obrolan?". Dari pertanyaan tersebut, diketahui sebanyak 239 responden menjawab "Ya", 39 responden menjawab "Mungkin", dan 4 responden menjawab "Tidak". Data tersebut data dilihat pada gambar berikut:

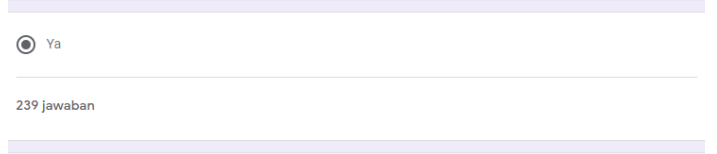

Mungkin

\section{9 jawaban}
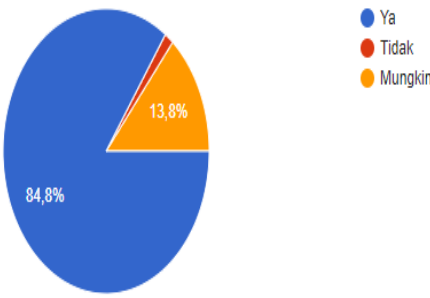

Gambar 5. Rekapitulasi data pertanyaan 5

Adapun untuk mendapatkan data terkait tantangan, peneliti mengajukan pertanyaan, "Apakah tugas yang diberikan pada pembelajaran melalui aplikasi obrolan dapat mengakomodasi pemahaman Anda terkait materi tersebut?". Dari pertanyaan tersebut, diketahui sebanyak 139 responden menjawab "Ya", 127 responden menjawab "Mungkin", dan 16 responden menjawab "Tidak". Data tersebut data dilihat pada gambar berikut: 


\section{Implementation of Learning Principles in Distance Learning \\ through the WhatsApp Application \\ Windi Megayanti \\ Universitas Indraprasta PGRI}
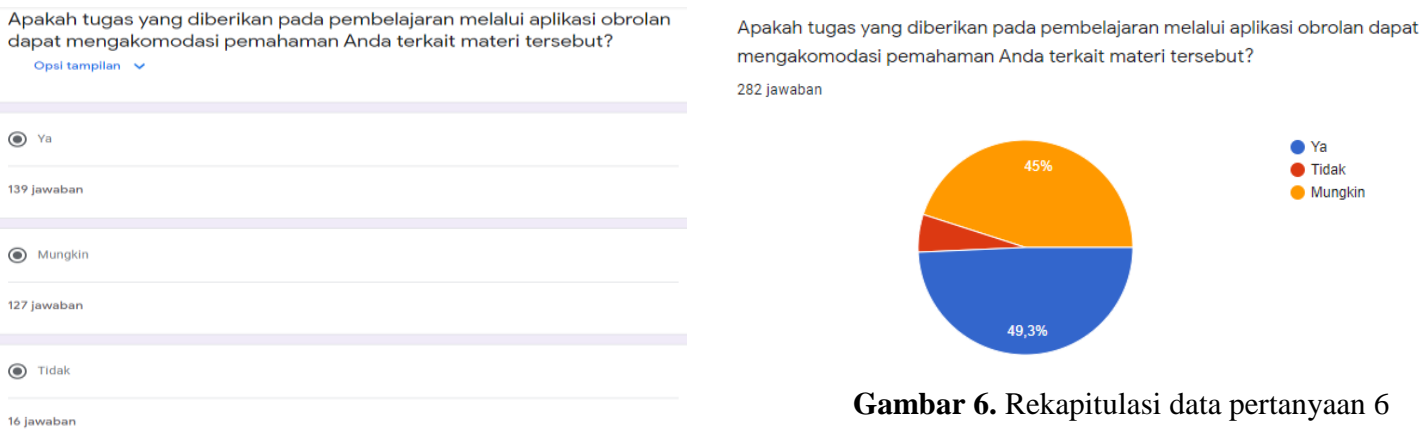

Gambar 6. Rekapitulasi data pertanyaan 6

Adapun untuk mendapatkan data terkait perbedaan individu, peneliti mengajukan pertanyaan, "Apakah kerumitan yang Anda hadapi dalam pembelajaran dapat terpecahkan dengan baik (entah memahaminya sendiri atau bertanya langsung pada dosen)?". Dari pertanyaan tersebut, diketahui sebanyak 153 responden menjawab "Ya", 108 responden menjawab "Mungkin", dan 21 responden menjawab "Tidak". Data tersebut data dilihat pada gambar berikut:
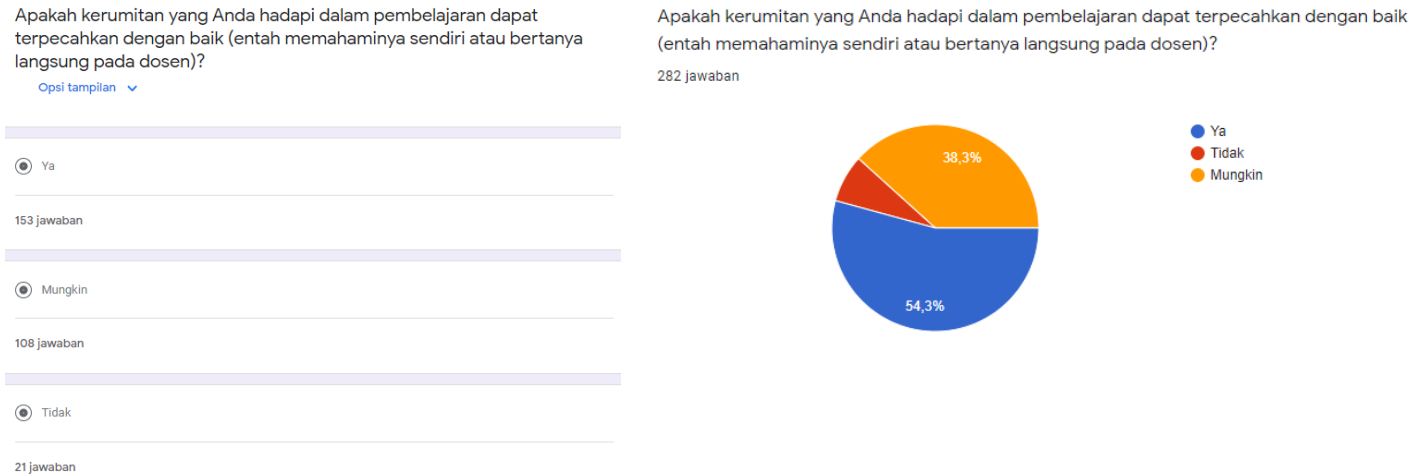

Gambar 7. Rekapitulasi data pertanyaan 7

\section{Pembahasan}

Penerapan prinsip-prinsip pembelajaran akan menentukan kesuksesan dalam pembelajaran. Melalui penerapan prinsip-prinsip pembelajaran, seorang pengajar akan dapat mengungkap batas-batas kemungkinan dalam pembelajaran sehingga mampu mengambil tindakan yang tepat (Bahtiar, 2016). Terlebih, kondisi saat ini yang menuntut pengajar terus melakukan pembelajaran meski situasi dan teknologi terus berkembang dengan cepat. Seperti yang dikatakan Pangondian, Santosa, \& Nugroho (2019) era revolusi industri 4.0, di mana IoT (Internet of Things) memegang peran penting dalam segala aspek, dunia pendidikan harus mulai mengikuti perkembangan tersebut. Banyak manfaat didapat dari pembelajaran secara daring salah satunya adalah tidak terkendala jarak dan waktu. Sayangnya, penerapan pembelajaran jarak jauh yang terpaksa dilakukan akibat pandemi Covid-19 ini bukan tanpa kendala. Banyak pengajar yang sekadar "asal online" dan mengagungkan media yang digunakannya. Rosadi (2021) mengatakan seyogianya para pengajar menyadari bahwa terpenting adalah menerapkan prinsip- 
prinsip pengajaran. Mengajar adalah sebuah proses menjadikan seseorang yang tidak tahu menjadi tahu.

Berdasarkan hasil penelitian implementasi prinsip-prinsip pembelajaran dalam pembelajaran jarak jauh melalui aplikasi obrolan WhatsApp, diketahui sebanyak 81,9\% mahasiswa menyatakan dapat memperhatikan pembelajaran dengan baik, 52,5\% mahasiswa merasa termotivasi saat mengikuti pembelajaran, 69,5\% mahasiswa menyatakan mampu mengikuti pembelajaran secara aktif, 62,4\% mahasiswa menyatakan merasa terlibat saat pembelajaran berlangsung, 84,8\% menyatakan dapat mengakses kembali materi yang telah dipelajari, 49,3\% menyatakan tugas yang diberikan dapat mengakomodasi pemahaman mereka, dan 54,3\% menyatakan bahwa kerumitan pembelajaran dapat dipecahkan melalui pembelajaran via WhatsApp. Berdasarkan temuan tersebut, dapat diketahui bahwa prinsip tertinggi yang diimplementasikan pada pembelajaran jarak jauh melalui aplikasi obrolan WhatsApp adalah prinsip pengulangan. Hal ini terlihat dari $84,8 \%$ responden menyatakan dapat mengakses kembali materi yang telah dipelajari meski pembelajaran dilakukan melalui aplikasi obrolan WhatsApp. Namun, prinsip tantangan yang diimplementasikan masih tergolong rendah. Hal ini terlihat dari hanya $49,3 \%$ responden menyatakan tugas yang diberikan dapat mengakomodasi pemahaman mereka.

\section{PENUTUP}

Berdasarkan penelitian tersebut maka dapat disimpulkan bahwa prinsip-prinsip pembelajaran seperti perhatian dan motivasi, keaktifan, keterlibatan langsung, pengulangan, tantangan, serta perbedaan individu telah diimplementasikan dengan baik meski pembelajaran dilakukan secara jarak jauh melalui aplikasi obrolan WhatsApp. Akan tetapi, pengajar tampaknya perlu memperhatikan tantangan dan perbedaan individu dalam pelaksanaan pembelajaran jarak jauh melalui WhatsApp ini. Hal ini terlihat dari hasil penelitian bahwa tugas yang diberikan dengan tujuan mengakomodasi pemahaman ternyata menunjukkan angka terendah, bahkan tidak mencapai 50\%. Hal ini menunjukkan bahwa perlu adanya inovasi lain dalam upaya mengakomodasi pemahaman agar dapat memfasilitasi setiap individu yang memiliki perbedaan dalam memahami setiap materi yang diberikan.

\section{DAFTAR PUSTAKA}

Ali, G. \& Hasniyati, S. (2013). Prinsip-prinsip Pembelajaran dan Implikasinya terhadap Pendidik dan Peserta Didik. Al-Ta'dib 6(1), 31-42.

Bahtiar, A. R. (2016). Prinsip-prinsip dan Model Pembelajaran Pendidikan Agama Islam. Tarbawi, 1(2).

Megayanti, W. \& Rosadi, N. (2018). Pengaruh Kepemilikan Handphone terhadap Uang Saku Peserta Didik untuk Pembelian Pulsa Paket Internet di SMK Yamas Jakarta. Research and Development Journal of Education (RDJE), 5 (1). 25-45. https://journal.lppmunindra.ac.id/index.php/RDJE/article/view/3386/2370

Pangondian, R. A., Santosa, P. I., \& Nugroho, E. (2019, February). Faktor-faktor yang mempengaruhi kesuksesan pembelajaran daring dalam revolusi industri 4.0. In Seminar Nasional Teknologi Komputer \& Sains (SAINTEKS) (Vol. 1, No. 1).

Prajana, A. (2017). Pemanfaatan Aplikasi Whatsapp untuk Media Pembelajaran dalam Lingkungan UIN Ar-Raniry Banda Aceh. Cyberspace, 1 (2). 122-133. http://dx.doi.org/10.22373/cs.v1i2.1980 


\section{Implementation of Learning Principles in Distance Learning \\ through the WhatsApp Application \\ Windi Megayanti \\ Universitas Indraprasta PGRI}

Pustikayasa, I. M. (2019). Grup WhatsApp Sebagai Media Pembelajaran. Widya Genitri : Jurnal Ilmiah Pendidikan, Agama Dan Kebudayaan Hindu, 10(2), 53-62. https://doi.org/10.36417/widyagenitri.v10i2.281

Robbani, H., Rosadi, N., \& Nurfitria, O. (2020). Creating a Learning Management System at the Smart Bangun Negeri Community Learning Activity Center. KANGMAS: Karya Ilmiah Pengabdian Masyarakat, 1(2), 75-78. https://doi.org/10.37010/kangmas.v1i2.52

Rosadi, N. (2021). Problems of Online Learning during the Covid-19 Pandemic. Duconomics Sci-meet (Education \& Economics Science Meet), 1, 8-14. https://doi.org/10.37010/duconomics.v1.5300

Sappaile, B. I. (2010). Konsep Penelitian Ex-Post Facto. Jurnal Pendidikan Matematika, 1 (2). 1-14. https://www.researchgate.net/profile/Baso-IntangSappaile/publication/338630818_KONSEP_PENELITIAN_EX-

POST_FACTO/links/5e206fcda6fdcc10156f629e/KONSEP-PENELITIAN-EX-POSTFACTO.pdf 